\title{
A Strategic Investment Decision: “Internationalization of SMEs”: A Multiple Appraisal Approach and Illustration with a Case Study
}

Asuman Atik

Department of Business Administration, Marmara University, Istanbul, Turkey.

Email: aatik@marmara.edu.tr

Received March 2 ${ }^{\text {nd }}, 2012$; revised March 12 ${ }^{\text {th }}, 2012$; accepted April $1^{\text {st }}, 2012$

\begin{abstract}
In a highly competitive environment, internationalization is a very attractive strategic investment for all types of firms. However, making the decision on internationalization, like other strategic investments, is very difficult because of high uncertainties and risks. Additionally, decision making process should include the evaluation of the strategic outcomes of internationalization. This study offers to integrate real options analysis into financial analyses in order not to overlook the strategic benefits of internationalization alternatives. A clear-cut approach which includes discounting methods and real options analysis is suggested and explained with a case study.
\end{abstract}

Keywords: Strategic Investment Decisions; SIDs; Discounting Methods; Real Options Analysis; Internationalization; SMEs

\section{Introduction}

High and aggressive competition among companies, rapidly expanding multinational firms, developments in the transportation and communication technologies are forcing small and medium enterprises (SMEs) to develop new strategies to stay alive in an international environment. Internationalization is not only remedy to stay alive for many firms, it also provides high profit potential if managed properly. New markets, new customers, cheaper resources, cheaper factors of production, improved strength and competitiveness of firms are some of the benefits of internationalization. Therefore internationalization is an attractive strategic investment for all types of firms, small or big, private or public.

Strategic investment decisions (SIDs) have substantial effects on the long term financial and operational performance of companies [1], and have a big impact on the competitive advantage of firms [2]. As one of the strategic investment decisions, internationalization is one of the most important and most complex decisions. It has its unique risks, uncertainties in the process are high and making estimations about future cash flows is very hard.

In order to make a sound internationalization decision, decision makers should make good estimations on many variables, such as market demand, offer price, exchange rates, future economic and political conditions of the new market. Estimating those variables becomes even harder when the firm is unfamiliar with the new market. Studies in that area pointed out the importance of knowledge in a successful internationalization.

Besides making good estimations on many variables, it is also very important to evaluate strategic implications of internationalization. Investment appraisal methods which have only financial perspectives and don't include strategic considerations are heavily criticized in the related literature. Many researchers suggest the inclusion of strategic evaluation into the appraisal methods. Although there are many theoretical studies, just a few show how strategic factors might be included into the analyses in a real world situation [3].

Main objectives of this study are to stress the importance of internationalization decision making process as one of the strategic investment decisions and to provide a guide for SMEs in the evaluation of their internationalization alternatives financially and strategically. In the light of previous studies, the usage of multiple appraisal approach which includes discounting methods and real options analysis is suggested. Adding real options into the appraisal process helps managers to see strategic implications of the investments from a better perspective.

The studies which searched the relationship between "size" and "appraisal methods used by firms" found that small firms prefer easier and less complex methods [4-7]. Therefore we kept the suggested approach as simple as 
possible because it is suggested as a guide for small and medium sized enterprises. Additionally, in this study we do not aim to guide firms in the selection of markets and/or entry modes, rather we assume that they have made their choices about markets and entry modes, and they are at the stage of financial evaluation and comparison of these alternatives.

The following part summarizes the related literature, part three explains the suggested approach with an illustrative case study, and last part includes the concluding remarks.

\section{Literature Review}

\subsection{Internalization and SMEs}

Internationalization is defined by Beamish [8] as "the process by which firms both increase their awareness of the direct and indirect influence of international transactions on their future, and establish and conduct transactions with firms in other countries". Internationalization is one of the challenges that firms must undertake in order to survive in an increasingly global environment [9].

Internationalization is a very complex strategy for all firms, however when unique characteristics of SMEs; such as inflexible structures, lack of strategic and financial resources, lack of managerial capabilities, lack of adequate information, and lack of adequate public support; are combined to the uncertainty and complexity of the internationalization process, the international expansion becomes even much harder [9-12].

Although the tendency to be risk-averse seems as a barrier for the small-firm internationalization, there are also many motives for international involvement such as; market seeking, efficiency seeking, strategic asset seeking and natural resource seeking [13], achieving economies of scale [14], and reducing revenue fluctuation by spreading investment risk over different countries [15].

There are different theories for the internationalization process, such as internationalization theory, networks theory, eclectic paradigm theory, transaction cost theory and resource based theory [16]. One of the oldest models for internationalization is the Uppsala Model, which says that the most important constraint is the lack of knowledge [17]. When the knowledge increases, the perceived uncertainty and risks diminish first, and then the international involvement and market commitment (the resources located in a market) increase. Therefore the Uppsala model talks about a step by step internationalization which starts with exports.

Although this model criticized by many researchers because this stepwise approach may not be suitable for each firm, there are also many researchers who propose this model especially for small and medium enterprises
[18]. According to Frynas and Mellahi [18] export is one of the simplest and most common approaches to enter foreign markets, and is preferred mainly by small firms to increase their knowledge about foreign markets. Other mentioned approaches for international involvement are licensing, franchising, joint ventures, mergers and acquisitions.

\subsection{Strategic Investment Decisions}

Strategic investment decisions (SIDs) are the decisions on investments which have substantial effects on the long term financial and operational performance of companies [1], and which have a big impact on the competitive advantage of firms [2]. Strategic investments generally have influence on the product or service sets of companies, and geographical scope and dispersion of their operations [2]. Company acquisitions and mergers, the introduction of new product lines, the installation of new manufacturing processes and business technologies are typical examples for SIDs in the related literature [19].

The complexity of SID making processes grabs the attention of researchers and academicians. While older studies develop models to evaluate investment projects only from financial perspectives, newer studies try to develop models that evaluate strategic outcomes of the investments and emphasize the importance of integrating financial and strategic analysis tools when making SIDs [2,19-24].

A large number of studies in the related literature also search which appraisal methods are being used to make investment decisions, which one is preferred most $[19,21$, 23,25-28] and what affects the method choice [1,4-6, $19,22,26,29]$. The mentioned factors that affect the method selection are size or characteristics of the company, type of the investment decision, management style, business environment, country that the company operates, and uncertainties faced.

\subsection{Investment Appraisal Methods}

In the related literature, we see different terminology for investment appraisal. In order to emphasize the strategic importance of internationalization, we prefer to use "strategic investment decision making”. However the literature survey comprehends "project appraisal", "project evaluation", "capital budgeting”, "strategic capital budgeting", "strategic investments" and "SIDs". Although there are numerous appraisal methods, only some selected ones are explained and strength and/or weaknesses of them are given in the following parts.

\subsubsection{Non-Discounting Methods: Payback Period and Accounting Rate of Return}

The payback period (PBP) is the number of years that the 
total cash inflows recover the initial cash outflow. This is a good method to see how quickly the initial investment amount will be collected however because it takes into account only liquidity but not the time value of money, it is highly criticized $[2,20,30]$.

Accounting rate of return (ARR) is based on the calculation of percentage of expected return on the initial investment. Total of accounting value of expected cash flows are deemed as the expected return on the initial investment, therefore sometimes it is interpreted as return on investment. This method also does not consider the time value of money and pattern and timing of the cash inflows [30]. Although it was popular in 1970s, some studies [26,31] showed the decrease in the usage of it among practitioners.

\subsubsection{Discounting Methods: Net Present Value and Internal Rate of Return}

Critiques on the non-discounting methods have forced the researchers to search for new investment appraisal methods. The theoretical foundation of time value by Fisher and derivation of weighted average cost of capital (WACC) as the discounting factor helped to the development of discounted cash flow methods, such as net present value (NPV) and internal rate of Return (IRR) [30,32].

NPV is calculated by subtracting estimated initial investment and the present value of estimated future cash outflows from the present value of estimated cash inflows. Present values are found by discounting the cash flows with an appropriate required rate of return which is generally WACC. When NPV is positive, the investment is acceptable, also when there are alternatives with different NPVs, the alternative that has the highest NPV should be chosen $[30,32,33]$.

IRR is the rate that equalizes the present value of estimated cash inflows with the initial investment amount. In other words, IRR is the rate when used as the discount rate, NPV becomes zero. Projects which have IRRs higher than their required rate of returns are acceptable. Additionally, IRR is the highest cost of financing of an investment $[30,32]$.

There are numerous critiques on those methods. NPV is criticized as being incompetent when comparing mutually exclusive projects which have different riskiness and cash inflow and outflow patterns [30]. NPV does not distinguish the investment that require high or low initial cash outflow and is biased to favor the projects with shorter payback periods and relatively higher initial cash inflows [3]. IRR is criticized as giving multiple rates when project cash flows are not only inflows, rather inflows are followed by outflows or vice versa [30]. A general critique on these discounting methods is that, in
NPV method, reinvestment rate of cash flows is assumed to be required rate of return, in IRR method, it is assumed to be project's IRR. However in reality reinvestment rates might be much different during the life span of the project, even the funds may even not be reinvested [32]. Having a narrow focus, short-termism, and especially being unable to assess and quantify strategic importance of the projects are among the most frequently mentioned problems of discounting methods.

In order to decrease the critiques on discounting methods, some researchers proposed some modifications. For example, modified IRR (MIRR) assumes that reinvestment rate of cash inflows from the investment will be required rate of return rather than IRR [3,32]. Present value index (PVI) which takes into account the level of discounted cash flows, adjusted present value and generalized adjusted value were other examples for the modifications of NPV [3].

\subsubsection{Financial Appraisal Profile Model}

After mentioning the inadequacies of existing non-discounting and discounting methods, especially in integrating strategic outcomes of investments into evaluation process, and pointing out the need for a new approach, Lefley [20] introduces his Financial Appraisal Profile (FAP) model. FAP model evaluates capital investment projects from three perspectives; financial, risk and strategic. It consists of nine components which are: 1) the capital cost of the project; 2) the cost of capital; 3) the project's estimated life; 4) NPV; 5) discounted payback (DPB); 6) discounted payback index (DPI); 7) marginal growth rate (MGR); 8) risk index; and 9) strategic index.

Lefley and Morgan [3] propose their model especially for medium sized enterprises because their model is practical rather than academic and easy to understand by smaller firms' managers who mostly rely on management intuition.

\subsubsection{Real Options Approach}

Real options approach which is based on the optionpricing model of Black and Sholes [34] has been developed in order to assess the value of flexibility (or having options) in a capital investment and widely accepted by academics. According to this model, having flexibility to expand, defer, downsize or quit a capital investment decision has some additional value because these options let companies to make their decisions or change them at some point in time according to their strategic and competitive opportunities [19].

When evaluating an investment decision, using DCF methods tells you "accept" or "reject" the investment "now" or "never". However in the real life, some projects have value because they create some additional invest- 
ment opportunities for the company or they have value only when they are delayed. For example, when a pharmaceutical company which evaluates an R \& D project by using NPV method may give a 'reject' decision, however if this R\&D project brings new investment and profit opportunities, this means by investing that negative-NPV R \& D project, this company is purchasing a "call option", right but not the obligation to take action, for future investment opportunities. Therefore real present value of the project in fact is higher than what NPV method tells [33].

"Defer", "abandon", "switch inputs, outputs or risky assets", "alter operating scale", "growth”, "staged investments", "process", and "market" are examples for the mentioned types of real options in the related literature [35-38].

$\mathrm{Li}$ and Rugman [39] cited that real options theory is applied to four main subjects in international business: the impact of multinationality on corporate performance, the advantages of joint ventures to enter a market, dynamic choice of market entry mode, and the optimal timing of investment decision.

Real options model takes into account only the moves of the investing company, not its competitors; however competitors' actions may affect the future value of the option. In order to integrate the effect of "not being the first mover" into the analyses, some studies use a game theoretic real options approach $[4,37,40,41]$.

\subsection{Risk and Uncertainty}

Risk is the probability of receiving an actual return which is different than expected. When there is variability in the expected returns, it means that the risk of the investment is high. Thus, investment risk can be measured by the variability in returns [32]. Although they are not the synonymous, risk and uncertainty are generally used interchangeably. Risk is a probability of undesirable outcome but uncertainty implies the unknown probability of outcomes, therefore risk carries a negative meaning in itself [20].

In order to deal with risk and uncertainty in investment decisions, many methods and approaches have been suggested by researchers, such as adjusting discount rate, adjusting forecasted cash flows, using computer simulation (Monte Carlo), certainty equivalents, beta analysis (CAPM), sensitivity analysis, scenario planning, probability analysis (decision trees), real options model and fuzzy sets $[4,19,20,23,24,27,36,42-44]$. Although some of these approaches are deemed more scientific, such as beta analysis, according to Alkaraan and Northcott [19], practitioners insist on using simpler and less sophisticated approaches, such as adjusted required rates of re- turn, shortened payback periods and probability analysis.

None of the suggested methods is accepted as the perfect method, all of them have some positive or negative sides. For example, some researchers argue that when an investment is deemed risky, cash flow assumptions are made accordingly, and adjusting the discounting rate means the effect of risk is included in the analysis twice. Sensitivity analysis is easy to apply but in real world it is hard to see that only one of the risk elements is changing, rather we see simultaneous up and downs of the elements. Beta analysis hard and technical, valuing options are not easy. And none of them exactly says "invest” or "don't invest”.

\section{The Suggested Multiple Appraisal Approach for the Internationalization Decision of SMEs}

When the investment decision has a strategic importance and long-term focus, there are more uncertainties and more risks, which make the decision making processes harder and more complicated. "Internationalization" decision, as one of the SIDs, has even more risks and uncertainties that are unique to it, such as the exchange rate fluctuations, political ambiguities, financing difficulties, additional operational costs, the lack of knowledge of new markets and consumer expectations, high inflation, low purchasing power in the new market and so on.

The study of Verbeeten [4] showed that when there are high financial uncertainties (exchange rate, interest), firms are more eager to use sophisticated methods and multiple risk adjustment tools simultaneously. Verbeeten was not the only researcher that supported the use of multiple methods, many researchers [2,3,21,22] also stressed the importance of integrating financial and strategic analysis tools when making SIDs.

Additionally, empirical findings of many studies $[4,6,7]$ showed that company size is related to the usage and perceived importance of sophisticated methods. Larger firms are more likely to use more complex and more sophisticated methods, maybe because they have easy access to administrative innovation and managerial experience.

In the light of previous studies, we suggest the usage of multiple investment appraisal methods and risk adjustment tools in the internalization decision making. Because our purpose is to propose our model as a guide for SMEs, we kept the selected methods and tools as simple as possible. Additionally, in this study we do not aim to guide firms in the selection of markets and/or entry modes, rather we assume that they have made their choices about markets and entry modes, they have determined their alternative internationalization strategies 
and they are at the stage of financial evaluation and comparison of these alternatives.

\section{Steps in the Suggested Multiple Appraisal Approach}

At the beginning, a team which has members from all departments of the firm to execute the internationalization process should be established. Because internationalization is a complex process, opinions of each department managers are very important. This will also help to analyze the costs, benefits, risks and strategic opportunities of internationalization in a better way.

The first step of the approach, as summarized in Figure 1, is the determination of new markets (countries and regions) and entry modes. A firm may determine more than one alternative, such as exporting to Country A, exporting to Country B, having a joint venture in Country D, purchasing a subsidiary in Country E. Generally these alternatives are not mutually exclusive, but firm resources may be a limiting factor, so sound evaluation and comparison of the alternatives and choosing the best one/ones is important.

The second step of the approach is the evaluation of the alternatives by using traditional discounting methods; NPV, IRR, Discounted Payback and Discounted Cash Flows Index. Although there are many critics on those methods, studies showed that they are still widely used and benefitted by the practitioners. Discounted payback is included in order to see how quickly initial investment will be recovered, and discounted cash flow index is to see how many times the initial investment will be recovered during the life of the investment.

While applying these methods, making good estimations on the cash flows, discount rate, life of the project is important. In an internationalization project, estimation of cash flows, especially, cash inflows is extremely hard.

Expected sales amount is affected by tastes, preferences and purchasing power of the new customers, competition in the new market and the economic conditions of the host country. Because it is a new market for the firm, although very crucial, making good estimations on those variables are hard. Additionally, if the currencies of home and host country are different, then there is a need to convert estimated foreign currency cash flows into home currency. At that point, the need for making good estimations about exchange rate changes arises. Income tax rates, import, export and foreign direct investment policies (tariffs, trade barriers and supports) of host governments are other variables that affect future cash flows.

On the cash outflows side, if the firm is operating at or near its full capacity, an increase in sales and production amounts necessitates new investments to increase pro- duction capacity. Although Lefley and Morgan [3] argue that these kinds of cash outflows should not be taken into analysis because they are related to firm's infrastructure investment, we do not agree. Additional investment also means additional funding requirements and an increase in cost of borrowing and weighted average cost of capital. These points should not be overlooked while making the analyses.

Weighted average cost of capital is the suggested rate for discounting. If the perceived riskiness of the alternative is high, then a higher discount rate should be used, so the analyzer can determine different NPVs at different perceived risk levels by using adjusted discount rates. In order to deal with risk and uncertainty, besides adjusting the discount rate, we propose scenario planning. The analyzers should expand their estimations to describe different (i.e. best, normal and worst) possible situations.

The third step includes the real options analysis. Each alternative should be analyzed in terms of potential options they create for the company. Cost of the options and expected benefits from the options should be tried to estimate as close as possible. For example, let's say there is a good alternative with positive NPV, high IRR and short PB. Although financial analysis points "take action", an option analysis may point "defer", if the analyzer believes that waiting and having time helps to decrease the risks and uncertainties and creates a better alternative. In such a case, the cost of the option is the NPV of the abandoned alternative and the value of the option is NPV of the second alternative which will be created by this defer option. As mentioned in the literature review part, the analyzer should not miss the importance of being the first mover while purchasing the defer option, and should care about the steps of competitors in home and host markets. Therefore we propose a gametheoretic real options analysis.

The fourth step is choosing the best alternative or alternatives according to the results of financial and real options analysis. The results may show that there are many profitable alternatives, in such a case the firm may choose to implement all of them or some of them. In general, internationalization moves are independent alternatives; however limited resources may be one factor that hinders the acceptance of all good alternatives.

The suggested approach is summarized in Figure 1 and illustrated in the following case study.

\section{Illustrative Case Study}

After Atik, Inc. is a medium-sized business entity located in Istanbul, Turkey. The new GM thinks that, now it is time to enter into international business. She assigned a team, which has members from marketing, production, 
Step 1: Selection of The New Markets (Countries or Regions) to enter and entry modes

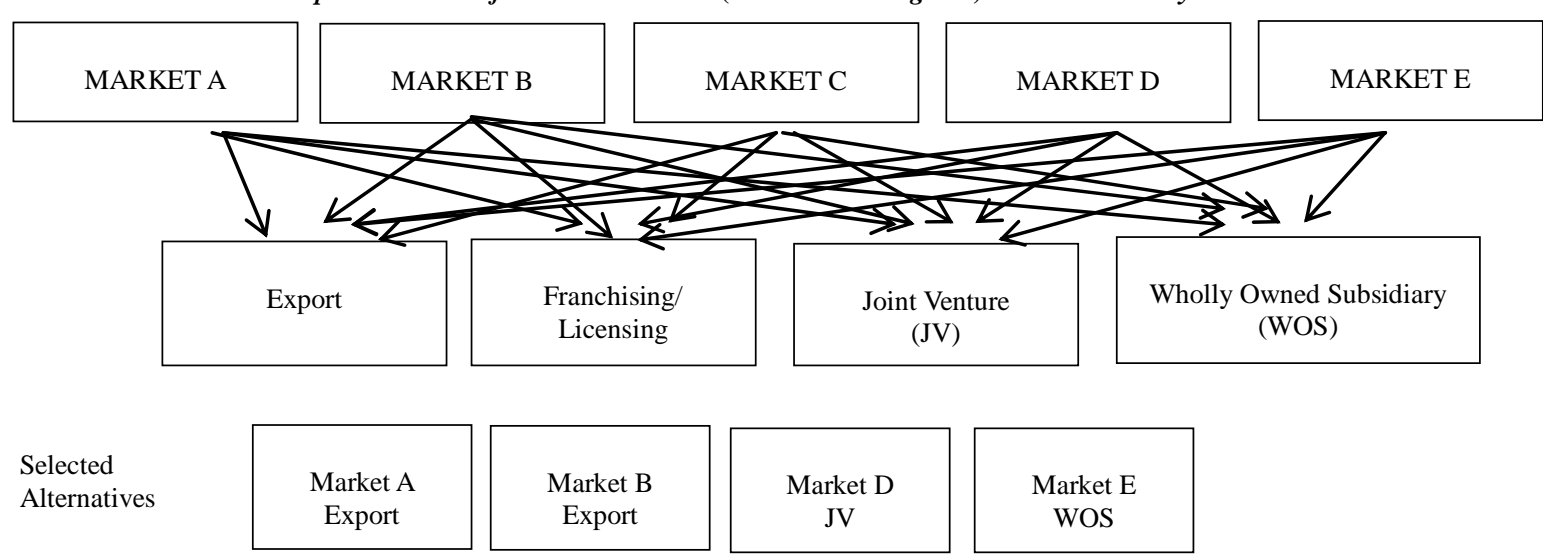

Step 2: Evaluating Selected Alternatives with Traditional Appraisal Methods

\begin{tabular}{|c|c|c|c|}
\hline $\begin{array}{c}\text { Alternative } 1 \\
\text { Market A } \\
\text { Export }\end{array}$ & $\begin{array}{c}\text { Alternative } 2 \\
\text { Market B } \\
\text { Export }\end{array}$ & $\begin{array}{c}\text { Alternative } 3 \\
\text { Market D } \\
\text { JV }\end{array}$ & $\begin{array}{c}\text { Alternative } 4 \\
\text { Market E } \\
\text { WOS }\end{array}$ \\
\hline
\end{tabular}
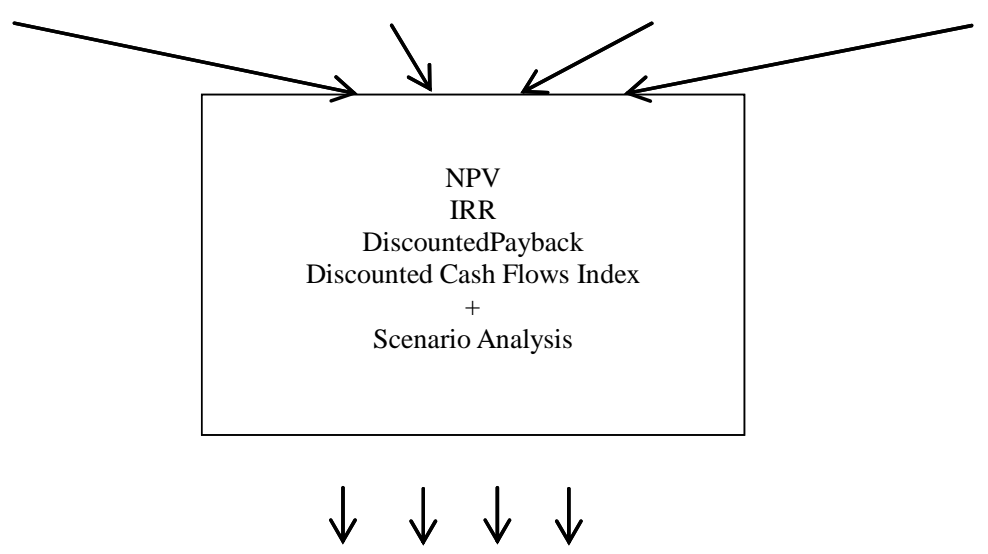

Step 3: Evaluating Selected Alternatives with Real Options Analysis

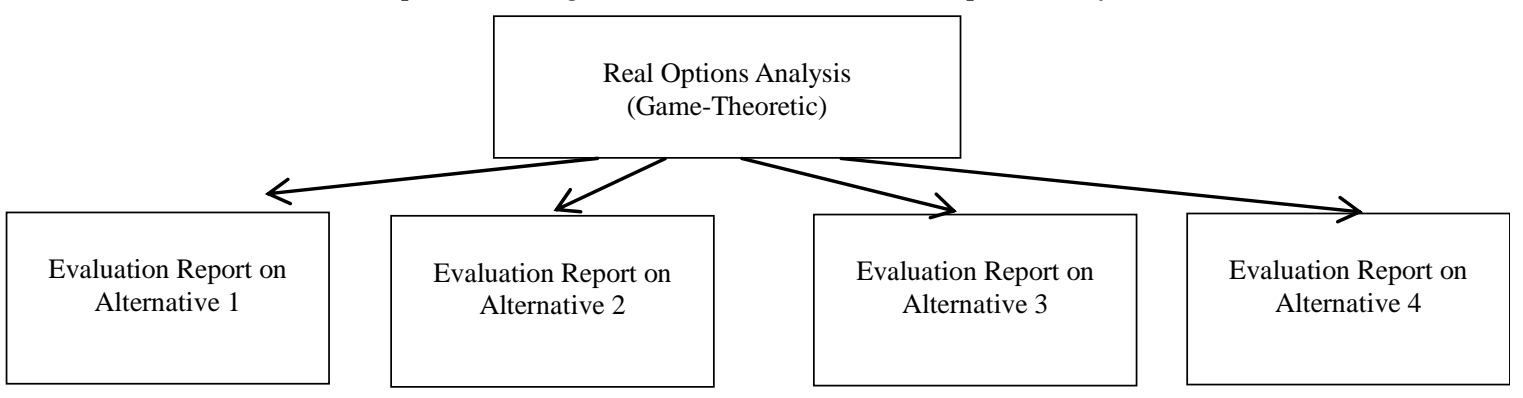

Step 4: Making the decision on internationalization and selecting the best alternative/alternatives

Alternative 1

Alternative 3

Figure 1. Summary of the suggested multiple appraisal approach.

strategic planning, finance and accounting departments, in order to execute the process.

Step 1: The team has decided to be conservative and go into international business with small steps. Only one neighbor country was selected as an initial market to go into international business. The team determined three 
alternatives: 1) exporting to that county, 2) having a joint venture in that country and 3) having a subsidiary in that country.

Step 2: Because the firm is operating nearly at its full capacity, it needs to make capital investment even if it chooses exporting. The following tables summarize the analyses. WACC was selected as the discount rate. The third alternative requires a heavy initial investment which will cause an increase in the WACC of the firm. Therefore the required rate of return is $16 \%$ for the first and second alternatives, $18 \%$ for the third alternative. Cash flow estimations were made for 20 years at most, because estimating cash flows longer than that period is very difficult.

As seen on Tables $\mathbf{1}$ and 2, the analyses show that the first and second alternatives are acceptable, but the third alternative should be rejected according to the results of the analyses seen on Table 3, and alternative 1 is better than alternative 2. Alternatives 1 and 2 were evaluated separately. Both have positive NPVs, but accepting both of them creates a third situation, which is exporting and having JV simultaneously. Sales revenue in that third situation might be different (lower) than the total of sales revenues of the first and second alternatives. Therefore alternatives 1 and 2 should be considered as mutually exclusive. Additionally, the team should also continue with real options analysis before making the decision.

Step 3: In that step each alternative should be evaluated in terms of option value they create. The team has recognized "defer" and "growth" options of the alternatives.

\subsection{Defer Option}

The team members think that they have much information and knowledge about the new market, purchasing a defer option, in other words waiting before expanding the firm capacity for exports or before having a JV agreement do not create much value for the company. The cost of the option is the time value of the net cash flows that are deferred. The team estimates that:

Cost of defer option of Alternative 1>

Value of defer option of Alternative 1

Cost of defer option of Alternative $2>$

Value of defer option of Alternative 2

Table 1. Appraisal of the first alternative with discounting methods and scenario analysis.

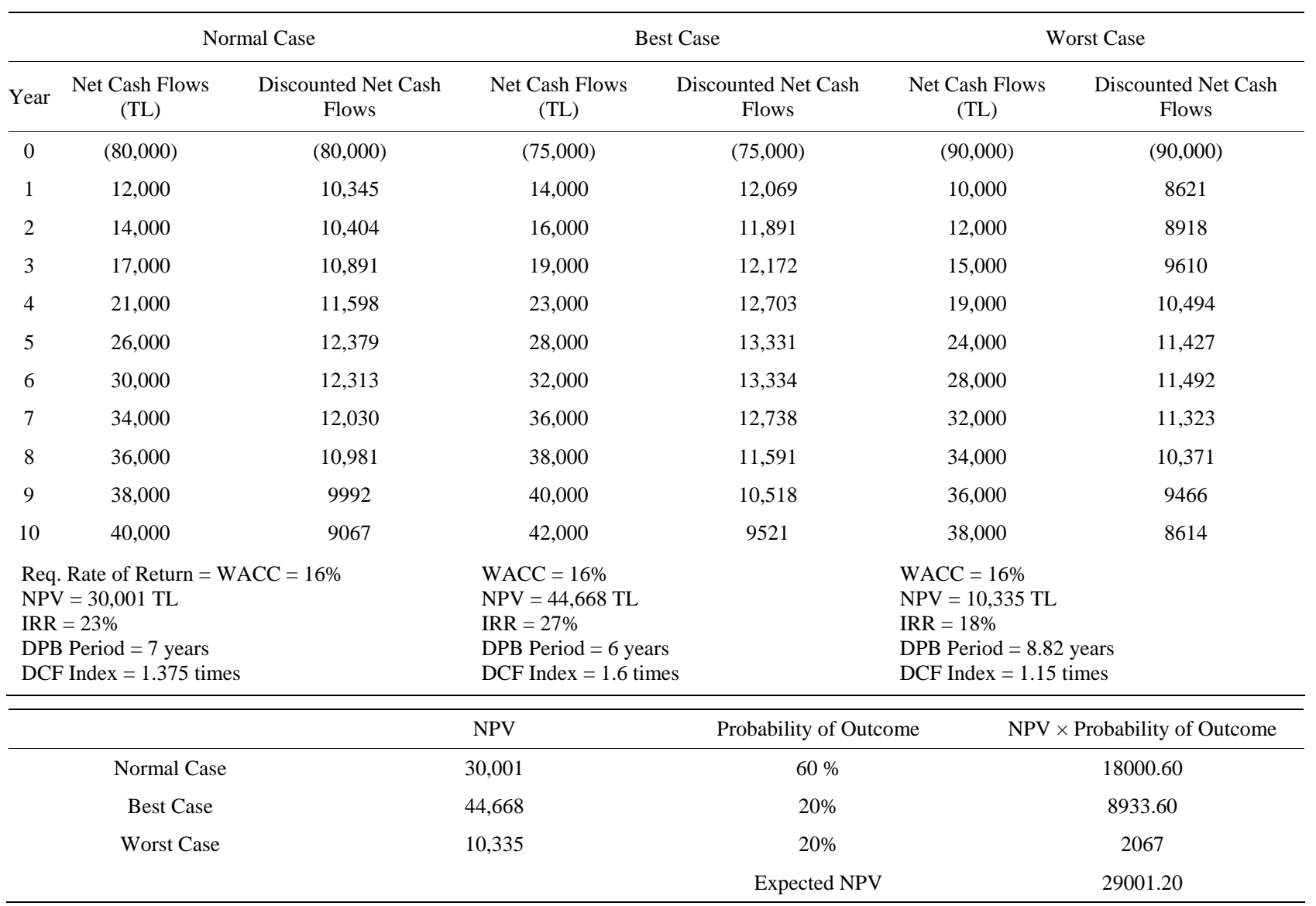


Table 2. Appraisal of the second alternative with discounting methods and scenario analysis.

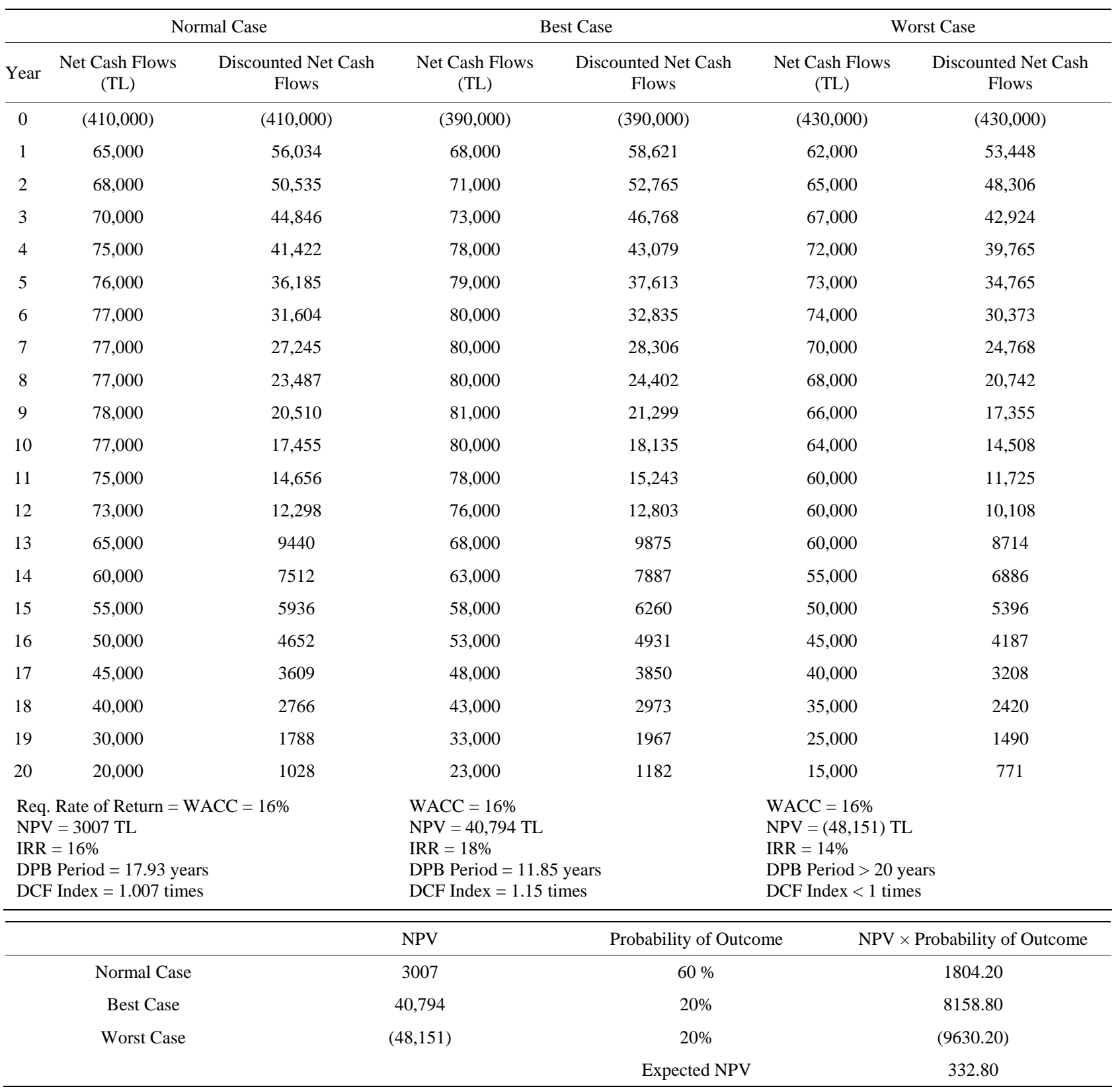

Therefore team chooses not to purchase defer option for Alternatives 1 and 2.

For WOS alternative, waiting may create value. Having better estimates about the future cash flows, and seeing profit potential may necessitate financial analysis again. The cost of defer option of Alternative 3 is zero, because this alternative does not seem profitable now and accordingly the firm does not lose money if it defers WOS investment. The team is sure about that the value of defer option is higher than the cost of it but they are not optimist about the value of it. This market is small and having a heavy investment is not attractive for the firm. Most probably this option will not be exercised.

Cost of defer option of Alternative $3<$

Value of defer option of Alternative 3

\subsection{Growth Option}

The team members have consensus on that the firm's ultimate aim is in fact to use this new market as a gate to its neighborhood, which has bigger, more attractive and more profitable markets. JV alternative has a very valuable growth option. Being experienced in the international 
Table 3. Appraisal of the third alternative with discounting methods and scenario analysis.

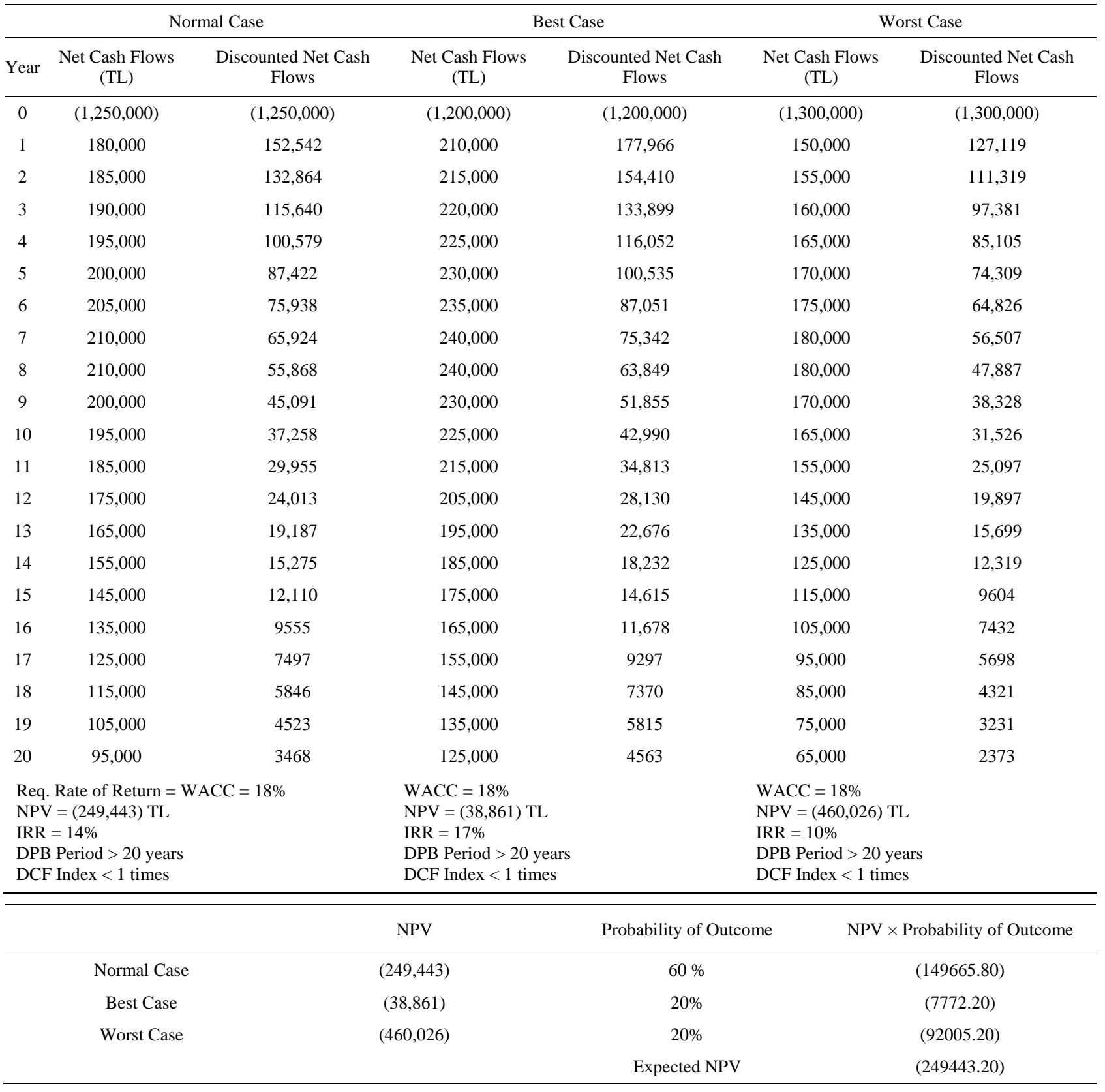

business will improve the abilities of the firm and will make it easier to understand foreign markets and customers. Additionally, and more important, the firm will be an international firm, its image will be improved and making $\mathrm{JV}$ agreements in other neighborhood markets will be easier. In the light of these, the team tried to estimate the cost and value of the growth option.

The team thinks that one year later, the firm has potential to spread over three countries which are culturally and geographically close to the new market. Cash flow estimations and financial calculations showed that, at worst case, these potential business has 875,000 TL NPV, and 19\% IRR. Therefore holding this option and exercising it in the future will add value to the firm. The cost of the option is the difference between the NPVs of the two alternatives.

Cost of growth option of Alternative $2<$

Value of growth option of Alternative 2

29001.20 TL - 332.80 TL < 875,000 TL

Step 4: At this last step, the team should decide on the best alternative in the light of financial and real options 
analysis. Without making real options analysis, the decision would be "choose the first alternative", but now the team decided to purchase a 'growth' option and chose the second alternative.

\section{Conclusions}

In a highly competitive environment, internationalization is not only necessary to stay alive but also important to gain competitive advantage. The SMEs which decide to go international should be aware of the risks and uncertainties that are waiting for them besides the advantages. Therefore they should take their steps very carefully. It is very important to make sophisticated appraisals and evaluate internationalization alternatives in every aspect, especially from financial and strategic.

Traditional methods generally evaluates investments from only financial perspectives, however in the related literature we see that there is a consensus among many researchers on the integration of strategic evaluation tools into financial analyses. The current study aimed to stress the importance of internationalization decision making process as one of the strategic investment decisions and to provide a guide for SMEs in the evaluation of their internationalization alternatives.

In the light of previous studies, a multiple appraisal approach which includes discounting methods and real options analysis was suggested. An illustrative case study showed that an alternative with a lower NPV in fact may be the best alternative when the real options it creates are evaluated.

Future studies should develop illustrative cases with different scenarios, or the scenarios might be taken from the real life. Previous internationalization decisions of SMEs may also be evaluated under the light of this new approach and the results may be compared.

\section{REFERENCES}

[1] C. Carr and C. Tomkins, "Strategic Investment Decisions: The Importance of SCM: A Comparative Analysis of 51 Case Studies in U.K., U.S. and German Companies," Management Accounting Research, Vol. 7, No. 2, 1996, pp. 199-217. doi:10.1006/mare.1996.0012

[2] R. W. Adler, "Strategic Investment Decision Techniques: The Old and the New," Business Horizons, Vol. 43, No. 6, 2000, pp.15-22. doi:10.1016/S0007-6813(00)80017-8

[3] F. Lefley and M. Morgan, “A New Pragmatic Approach to Capital Investment Appraisal: The Financial Appraisal Profile," International Journal of Production Economics, Vol. 55, No. 3, 1998, pp. 351-341. doi:10.1016/S0925-5273(98)00089-9

[4] F. H. M. Verbeeten, "Do Organizations Adopt Sophisticated Capital Budgeting Practices to Deal with Uncertainty in the Investment Decision? A Research Note,"
Management Accounting Research, Vol. 17, No. 1, 2006, pp. 106-120.

[5] N. Hermes, P. Smid and L. Yao, "Capital Budgeting Practices: A Comparative Study of the Netherlands and China," International Business Review, Vol. 16, No. 5, 2007, pp. 630-654. doi:10.1016/j.ibusrev.2007.05.002

[6] D. Brounen, A. De Jong and K. Koedijk, "Corporate Finance in Europe: Confronting Theory with Practice,” Financial Management, Vol. 33, No. 4, 2004, pp. 71-101.

[7] P. A. Ryan and G. P. Ryan, "Capital Budgeting Practices of the Fortune 1000: How Have Things Changed?” Journal of Business and Management, Vol. 8, No. 4, 2002, pp. 355-364.

[8] P. W. Beamish, "The Internationalization Process for Smaller Ontario Firms: A Research Agenda,” Research in Global Business Management, Vol. 1, 1990, pp. 77-92.

[9] J. C. Casillas, A. M. Moreno and F. J. Acedo, "Internationalization of Family Businesses: A Theoretical Model Base on International Entrepreneurship Perspective," Global Management Journal, Vol. 3, No. 2, 2010, pp. 18-35.

[10] J. L. Ward, "Growing the Family Business: Special Challenges and Best Practices,” Family Business Review, Vol. 10, No. 1, 1998, pp. 323-337.

[11] Z. Fernandez and M. J. Nieto, "Internationalization Strategy of Small and Medium-Sized Family Businesses: Some Influential Factors,” Family Business Review, Vol. 18 , No. 1, 2006, pp. 2-23.

[12] Internationalization of European SMEs, European Commission Report, 2010.

http://ec.europa.eu/.../sme/.../internationalisation_of_euro pean_smes_final_en.pdf

[13] R. Narula and J. Dunning, “Industrial Development, Globalization and Multinational Enterprises: New Realities for Developing Countries," Oxford Development Studies, Vol. 28, No. 2, 2000, pp. 141-167. doi:10.1080/713688313

[14] J. W. Lu and P. W. Beamish, "International Diversification and Firm Performance: The S-Curve Hypothesis," Academy of Management Journal, Vol. 47, No. 4, 2004, pp. 598-609. doi:10.2307/20159604

[15] W. C. Kim, P. Hwang and W. P. Burgers, "Multinationals' Diversification and the Risk-Return Trade-Off,” Strategic Management Journal, Vol. 14, No. 4, 1993, pp. 275286. doi:10.1002/smj.4250140404

[16] M. Asgari, Z. A. Syed and M. I. Gurrib, "Explaining the Internationalization Process of Malaysian Service Firms," International Journal of Trade, Economics and Finance, Vol. 1, No. 1, 2010, pp. 68-73.

[17] F. F. Lemos, J. Johanson and J. E. Vahlne, "Risk Management in the Internationalization Process of the Firm: A Note on the Uppsala Model," Journal of World Business, Vol. 46, No. 2, 2011, pp. 143-153. doi:10.1016/j.jwb.2010.05.008

[18] J. G. Frynas and K. Mellahi, "Global Strategic Management,” 2nd Edition, Oxford University Press, Oxford, 2011.

[19] F. Alkaraan and D. Northcott, "Strategic Capital Investment Decision-Making: A Role for Emergent Analysis Tools? 
A Study of Practice in Large UK Manufacturing Companies," The British Accounting Review, Vol. 38, No. 2, 2006, pp. 149-173. doi:10.1016/j.bar.2005.10.003

[20] F. Lefley, "Approaches to Risk and Uncertainty in the Appraisal of New Technology Capital Projects,” International Journal Production Economics, Vol. 53, No. 1, 1997, pp. 21-33. doi:10.1016/S0925-5273(97)00106-0

[21] M. M. Akalu, "The Process of Investment Appraisal: The Experience of 10 Large British and Dutch Companies," International Journal of Project Management, Vol. 21, No. 5, 2003, pp. 355-362.

[22] C. Carr, K. Kolehmainen and F. Mitchell, "Strategic Investment Decision Making Practices: A Contextual Approach”, Management Accounting Research, Vol. 21, No. 3, 2010, pp. 167-184. doi:10.1016/j.mar.2010.03.004

[23] M. G. Abdel-Kader and D. Dugdale, "Investment in Advanced Manufacturing Technology: A Study of Practice in Large U.K. Companies," Management Accounting Research, Vol. 9, No. 3, 1998, pp. 261-284. doi:10.1006/mare.1998.0071

[24] T. M. Alessandri, D. N. Ford, D. M. Lander, K. B. Leggio and M. Taylor, "Managing Risk and Uncertainty in Complex Capital Projects,” The Quarterly Review of Economics and Finance, Vol. 44, No. 5, 2004, pp. 751-767. doi:10.1016/j.qref.2004.05.010

[25] F. Lefley, "Capital Investment Appraisal of Advanced Manufacturing Technology,” International Journal Production Research, Vol. 32, No. 12, 1994, pp. 2751-2776. doi:10.1080/00207549408957098

[26] R. H. Pike, “A Longitudinal Survey on Capital Budgeting Practices,” Journal of Business Finance and Accounting, Vol. 23, No. 1, 1996, pp. 79-92. doi:10.1111/j.1468-5957.1996.tb00403.x

[27] G. C. Arnold and P. D. Hatzopoulos, "The Theory-Practice Gap in Capital Budgeting: Evidence from the United Kingdom,” Journal of Business Finance and Accounting, Vol. 27, No. 5-6, 2000, pp. 603-626. doi:10.1111/1468-5957.00327

[28] J. R. Graham and C. R. Harvey, "The Theory and Practice of Corporate Finance: Evidence from the Field,” Journal of Financial Economics, Vol. 60, No. 2-3, 2001, pp. 187-243. doi:10.1016/S0304-405X(01)00044-7

[29] C. Carr, “Are German, Japanese and Anglo-Saxon Strategic Styles Still Divergent in the Context of Globalization?” Journal of Management Studies, Vol. 42, No. 6, 2005, pp. 1155-1188. doi:10.1111/j.1467-6486.2005.00537.x

[30] M. M. Akalu, "Re-Examining Project Appraisal and Control: Developing a Focus on Wealth Creation,” International Journal of Project Management, Vol. 19, No. 1, 2001, pp. 375-383. doi:10.1016/S0263-7863(00)00019-3

[31] F. Lefley and J. Sarkis, "The Decline of the Accounting
Rate of Return (ARR)”, Management Accounting, Vol. 6, No. 1, 1997, pp. 50-52.

[32] J. F. Weston, S. Besley and E. F. Brigham, "Essentials of Managerial Finance,” 11th Edition, The Ddryden Press, New York, 1996.

[33] A. K. Dixit and R. S. Pindyck, "The Options Approach to Capital Investment," Harvard Business Review, 1995, pp. 105-115.

[34] F. Black and M. Scholes, "The Pricing of Option and Corporate Liabilities,” Journal of Political Economy, Vol. 81, No. 3, 1973, pp. 637-654. doi:10.1086/260062

[35] D. M. Lander and G. E. Pinches, "Challenges to the Practical Implementation of Modeling and Valuing Real Options,” The Quarterly Review of Economics and Finance, Vol. 38, No. 2, 1998, pp. 537-567. doi:10.1016/S1062-9769(99)80089-1

[36] D. E. Stout, H. Qi, Y. A. Xie and S. Liu, "Incorporating Real-Options Analysis into the Accounting Curriculum," Journal of Accounting Education, Vol. 26, No. 4, 2008, pp. 213-230. doi:10.1016/j.jaccedu.2009.03.002

[37] Y. C. Jan, "Strategic Investment in Taiwan Chain and Franchise Stores: A Real Options and Game-Theoretic Approach,” Global Journal of Business Research, Vol. 5, No. 4, 2011, pp. 25-37.

[38] J. Bengtsson, "Manufacturing Flexibility and Real Options: A Review," International Journal Production Economics, Vol. 74, No. 1-3, 2001, pp. 213-224. doi:10.1016/S0925-5273(01)00128-1

[39] J. Li and A. M. Rugman, "Real Options and the Theory of Foreign Direct Investment," International Business Review, Vol. 16, 2007, pp. 687-712. doi:10.1016/j.ibusrev.2007.08.004

[40] H. T. J. Smith and L. Trigeorgis, "Strategic Options and Games in Analyzing Dynamic Technology Investments," Long Range Planning, Vol. 40, No. 1, 2007, pp. 84-114. doi:10.1016/j.lrp.2007.02.005

[41] H. T. J. Smit and L. Trigeorgis, "Real Options and Games: Competition, Alliances and Other Applications of Valuation and Strategy," Review of Financial Economics, Vol. 15, No. 2, 2006, pp. 95-112. doi:10.1016/j.rfe.2005.12.001

[42] K. D. Miller and H. G. Waller, "Scenarios, Real Options and Integrated Risk Management,” Long Range Planning, Vol. 36, No. 1, 2003, pp. 93-107. doi:10.1016/S0024-6301(02)00205-4

[43] F. Cescon, "Investment in New Manufacturing Systems: An Italian-Based Empirical Analysis,” Economia Aziendale Online 2000 Web, Vol. 1, No. 1, 2010, pp. 13-26.

[44] C. Kahraman, D. Ruan and E. Tolga, "Capital Budgeting Techniques Using Discounted Fuzzy versus Probabilistic Cash Flows,” Information Sciences, Vol. 142, No. 1-4, 2002, pp. 57-76. doi:10.1016/S0020-0255(02)00157-3 